University of Nebraska - Lincoln

DigitalCommons@University of Nebraska - Lincoln

Faculty Publications, Department of Psychology

Psychology, Department of

November 1978

\title{
Attribution, Socialization, and Moral Decision Making
}

Richard A. Dienstbier

University of Nebraska-Lincoln, rdienstbier2@unl.edu

Follow this and additional works at: https://digitalcommons.unl.edu/psychfacpub

Part of the Psychiatry and Psychology Commons

Dienstbier, Richard A., "Attribution, Socialization, and Moral Decision Making" (1978). Faculty Publications, Department of Psychology. 67.

https://digitalcommons.unl.edu/psychfacpub/67

This Article is brought to you for free and open access by the Psychology, Department of at DigitalCommons@University of Nebraska - Lincoln. It has been accepted for inclusion in Faculty Publications, Department of Psychology by an authorized administrator of DigitalCommons@University of Nebraska - Lincoln. 


\title{
Attribution, Socialization, and Moral Decision Making
}

\author{
Richard A. Dienstbier \\ University of Nebraska, Lincoln
}

The position developed in this chapter resembles that taken by Aristotle more than that taken by most modern psychology theorists, for our discipline has tended to approach moral behavior and thought as if two quite different topics were at issue. Modern psychological approaches to moral behavior have tended to focus almost entirely on the emotional mediation of avoidance and upon avoidance behavior, whereas moral judgment theorists have tended to isolate themselves from both emotion and behavior, concentrating instead on verbal expressions of moral judgments. Aristotle suggested a more integrated view that effective moral training should first involve the young child's emotional dispositions, so that the child learned to love and hate correctly; later when maturation allowed reasoning to emerge, there would be a "symphony between habituated preferences and what reasoning shows to be good" (Fortenbaugh, 1975 , p. 49). In an attempt to account for that "symphony" between habituated preferences and reasoning in the realm of morality, this chapter's theoretical development deals with the interplay between emotions and cognitions about emotions, using emotion attribution theory concepts.

The initial issue of this chapter centers upon what constitutes a moral decision, and whether moral decisions and situations should be defined on the basis of specific significant behavior by the actor (e.g., cheating, stealing, killing) or upon a more complex basis. Research is presented that supports the more complex approach by demonstrating that when moral values are made salient, cheating (usually thought to be clearly morally relevant) either increases or decreases, depending on certain specific attributes perceived in the temptation context. It is concluded that a complex attributional analysis of situations from the individual's viewpoint is very important in establishing the relevance of moral values to decision making in various contexts. 
The largest portion of the chapter deals with research indicating that causal attributions about the sources and meaning of emotional arousal determine the impact of that emotional response in moral decisions and behavior for adults and children. Finally, the effectiveness of various socialization techniques for both normal and psychopathic individuals is analyzed, using emotion attribution concepts.

\section{DEFINING MORAL SITUATIONS}

What is morality? What constitutes a moral decision? What unique attributes must a situation appear to have before moral values and constructs are elicited? The issue is sufficiently complex that it is not solved by simply defining (as has Turiel, 1977) certain classes of behavior, such as helping others in distress, as arbitrarily relevant to morality, whereas other classes, such as not handling a forbidden toy, are not morally relevant.

For the purpose of this paper, a moral situation is defined as one that evokes significant guilt or shame when transgression occurs; normally, this will mean that a significant transgression of one's values has occurred or may occur. Moral self-control, on the other hand, will be defined as behavior where one resists temptation in a moral situation in spite of the perception that detection of transgression is not possible. One test of whether any situation is a moral one would be to determine whether the rate or frequency of moral behavior changed (appropriately) as moral values were made increasingly salient; the first section of this chapter addresses that issue. A second test of whether morality is perceived as relevant to a situation would be achieved by manipulating emotional arousal or attributions about arousal to ascertain whether moral behavior increased or decreased; the second and larger half of this chapter presents research using such techniques.

Whether an individual responds to a situation as a moral dilemma depends primarily upon the cultural, social, and individual context, for categories of behavior defined as morally relevant by one culture, society, or by one individual may not be similarly defined by others. Within the culture of "middle America," for example, situations involving theft, or others being hurt, may be perceived by most people as clearly calling for moral decisions, whereas less consensus as to moral relevance would exist for some other issues (e.g., sexuality or "hard work"). But even for a single individual it is likely that the temptation to perform a specific behavior in one situation might be considered a moral dilemma, whereas in another situation that same behavior would not be regarded as morally relevant. Consider the following example: A college student with the need and opportunity to cheat attributes the quality of unfairness to the test and the testing context. In that example, attributing the quality of "unfairness" might reduce the perception of moral relevance for the act of cheating, resulting in 
increased cheating. It should be apparent that a great variety of situational attributes could potentially affect the degree to which moral values and constructs are perceived to be relevant to the choices in a given situation. Such attributions about the meaning of each situation will undoubtedly affect the attributions about the nature and meaning of any emotional arousal experienced; attributions of both types will then influence the individual's behavior.

A series of studies are presented to illustrate the point that specific attributions made about temptation situations (rather than a specific behavior) determine whether an individual will respond to a temptation situation as a moral dilemma. Specifically, the research demonstrates the importance of attributes about the victim of cheating in making moral values relevant or irrelevant to cheating. The logic of the research is simple: If making moral values or norms salient for research subjects increases their tendency to cheat on an exam, then the act of cheating is not being perceived as morally wrong; on the other hand, if cheating decreases when morality is made salient - compared to a control group for whom morality is not made salient - the dilemma of whether or not to cheat is indeed a moral one. Besides being based on common sense, this approach is based on the research of Schwartz and his colleagues (Schwartz, 1976), who demonstrated increased helping behavior after altruistic values were made salient. Schwartz used the term norm activation to suggest that the norms governing altruistic behavior were already well internalized but were potentiated or activated by a technique that reminded subjects of those norms. In this paper, I shall continue to use the term value to mean norms that have been "internalized."

In the first study of the five-study series (Dienstbier, Kahle, Willis, \& Tunnell, 1977) done with the able assistance of Gil Tunnell, we initially attempted to explore aspects of emotion attribution theory that will be discussed in a later section of this chapter. However, the study led us down a theoretical path not initially intended. Freshmen male college students were recruited for a study on verbal skills and were subjected to a series of tests beginning with a vocabulary test; that test was followed by a reading comprehension test (the independent manipulation) and then with the opportunity to cheat (the dependent measure) on the vocabulary test. Three different versions of the reading comprehension test concerning the Minoan culture were constructed: The first versions described their high moral principles based upon personal values and guilt (the internal manipulation). The second version presented similarly high moral principles based upon social norms and shame (the external manipulation). The third version dealt with the high level of achievement of the Minoans (the control manipulation). As confirmed by an elaborate postexperimental questionnaire (such as used in all the reported studies), the later cheating situation was perceived by the subjects as free from possible detection. It was hypothesized that the moral values that were made salient would be effective in reducing cheating on the vocabulary test for the two groups of subjects who read about moral principles, 
in contrast to the (higher) cheating frequency of control subjects. [The reading comprehension passages were based upon an article by Davies (1969) on the achievements of the Minoans.]

In order to induce motivation to cheat on the vocabulary portion of the test, the subjects were told that typical college freshmen scored at least 18 right on the 30-item, multiple-choice test and that their performance on the test would be compared with their future college performance, since the "Board of Psychologists" developing the test thought that vocabularly scores would correspond with grades in certain courses. Subjects were seated in a row of booths so that the 6 to 10 subjects present for any one session could not see each other; cheating occurred as answer changing during a "delay" period after the test was over when the answers were available. Since subjects were told that the machinegradable answer paper for the vocabularly items must be marked darkly and be free of sloppy erasures, they had an excuse to use pencils during the "delay" period. However, they were warned (as in all the cheating research) not to change any answers. [The procedure for detecting cheating using pressure-sensitive paper is described in detail elsewhere (Dienstbier \& Munter, 1971).] The results were clearly contrary to the hypothesis; the control-condition subjects cheated less ( $21 \%$ of the 48 subjects cheated) than subjects in the other two conditions (33\% of the 43 internal-condition subjects cheated, and $43 \%$ of the 44 external subjects cheated). In other words, the activation of moral values by the internal and external reading comprehension passages increased rather than prevented cheating - a totally unexpected finding. An informal statistical analysis (Fisher Exact Test, two-tailed) was undertaken, indicating a significance level of $p=$ .06 between the control condition cheating rate and the combined rate for the internal and external conditions. It was not until after that effect was replicated with diverse procedures and materials that the finding was regarded as credible.

Since the results in that initial research were contrary to expectations, a second study was undertaken with different materials, again in an effort to study differences between cheating rates of the internal vs. ex ternal subjects, and with the control condition included merely for additional information. That study, done with the aid of Keith Willis, was carried out with freshmen female subjects and vastly revised independent manipulation ("reading comprehension") materials, though the vocabularly testing part and the cheating opportunity remained essentially the same as for Study 1 . Subjects were told that since they all had similar psychology backgrounds (being all in their first basic course), the reading comprehension test would deal with psychology topics (giving no one an unfair advantage). After reading and being tested on a passage on the sensation of touch, the independent manipulation passage was read. Internal- and externalcondition subjects read about the development of conscience. The external passage indicated that the final developmental step was completed when the individual experienced shame when detection for transgression was thought to be possible. The internal passage concluded that conscience was developed 
when guilt was experienced even when detection was impossible. Control subjects read about the development of immediate memory. A replication of the results of Study 1 was achieved, with almost identical cheating rates in the internal and external conditions (32\% of the 56 subjects in both conditions cheating) and with that rate considerably higher than that for the control subjects (14\% of the 29 subjects cheating, $p=.05$, Fisher's exact test, one-tailed).

With the unexpected results of both Studies 1 and 2, where increased cheating followed the activation of moral values, a more thoughtful analysis was undertaken of the situation as it was perceived by the subjects. In Studies 1 and 2, following procedures developed for other research (Dienstbier \& Munter, 1971; Dienstbier, 1972), subjects had been told that the vocabularly test was an experimental test being developed by a board of psychologists, and they were asked to put their social security number of their answer sheet, "just in case the board developing this test decides to compare your vocabularly test performance with your later grades in certain courses - so far they have found that most successful college students score at least 18 , as freshmen, on this 30 -item test; a chance score is $10 . "$

I began to suspect that the subjects perceived the research as basically unfair and that this unfairness could be offset by their cheating on the vocabulary test to achieve a score somewhat higher (and closer to 18) than they had achieved fairly. Furthermore, cheating against an anonymous "board of psychologists" might have seemed too impersonal a jesture to be morally relevant. Certainly similar logic is often used by individuals dealing with large institutions such as their government at tax time, insurance companies, etc. More cheating after moral value activation could be due to the subjects being able to make a clearer definition of morality following the reading of the conscience-oriented passages, so that their present situation could be more clearly defined as nonmoral. To test this notion, a third study was undertaken with materials and procedures identical to those used in Study 2, except that Keith Willis, who had acted as the experimenter in Study 2, remade our tape-recorded instructions in his voice and claimed that this research was for his Ph.D. dissertation. References to the "board of psychologists" were changed to " $I$ " in the instructions pertaining to the vocabulary test, and subjects were told: "Don't change any answers. I really need accurate data for my thesis, or I'll have to spend another semester trying." It was believed that those changes would cause subjects to redefine the situation as a moral one, with cheating an immoral behavior, so that moral value activation via the initial reading comprehension passages would result in reduced cheating. That prediction was realized with $12 \%$ of the 69 subjects in the two experimental groups cheating, compared with $29 \%$ of the 34 control-condition subjects ( $p=$ .03 , Fisher's exact test, two-tailed). The difference in cheating patterns between Studies 2 and 3, run in successive semesters but with the same experimenter and format except as described above, was statistically significant $(p<.005$ using an interaction test for arc-sine transformed percentages, two-tailed, developed by 
Langer and Abelson, 1972). The results of Study 3 were essentially replicated in a study to be reported below.

To buttress our confidence that the complete reversal in cheating pattern between Studies 2 and 3 was really due to the perception that cheating in Study 3 was perceived to be morally wrong, especially after reading about morality, I conducted a fourth study with Lynn Kahle. In Study 4, subjects participated in either the Study 2 or the Study 3 version of the procedure, except that when the opportunity to cheat occurred, we asked subjects to record their level of resentment toward either the "board of psychologists who developed the vocabulary test" in the Study 2 version or toward "Lynn Kahle who developed the vocabulary test" in the Study 3 version. Subjects were given the opportunity to respond on a 5-point scale with possible answers from "none" (scored 1) to "extreme" (scored 5). Those subjects in Study 2 (with the board of psychologists) were significantly more resentful than subjects in the Study 3 version (means of 1.98 vs. $1.43, F=7.08, p<.01$ ). Furthermore, as predicted, whereas subjects in the internal and external conditions of Study 2 were considerably more resentful than subjects in the comparable conditions of Study 3 (means of 2.13 vs. $1.47, t=2.77, p<.01$, two-tailed), resentfulness of control-condition subjects did not differ significantly between the studies (mean of 1.67 vs. $1.35, t=.89$, $N S$ ). The pattern of data therefore supports the contention that although subjects resented the "board of psychologists" considerably more than the graduatestudent researcher, their resentment was accentuated by the reading of the morally relevant reading comprehension materials.

The research presented above (along with a similar study presented below to explore other emotion-attribution issues) demonstrates that specific attributions that people make about potential moral dilemmas determine whether moral values (and by inference, avoidance-mediating emotions such as guilt and shame) are relevant to one's behavioral choices. Making morality salient in the research above either increased or decreased the number of subjects who saw the situation as morally relevant and who resisted the temptation to cheat.

Unfortunately, this research does not provide an easy key to the analysis of what situations will be perceived as moral ones for people in the real world or for research subjects in other settings. Instead, I am able to suggest only a research technique. When the researcher assumes that individuals will bring to bear certain values or constructs in response to the research situation, one method for checking that assumption is to preactivate those values or constructs to determine whether appropriate behavior is stimulated.

In the following section, in contrast, the manipulations were not relevant to the activation of moral values, so that we may assume that the subjects in the various research conditions were equally likely to perceive the moral implications of their behavior (often cheating) and were equally motivated to cheat. The issue of the following section and of the research described in it is how the quantity and quality of emotional arousal and experience affected moral selfcontrol. 


\section{EMOTIONAL AROUSAL AND MORAL BEHAVIOR}

The larger half of this chapter will deal with those emotion attribution processes that occur when an individual faces temptation to transgress against moral values. The first issue, addressed through the research reviewed immediately below, is whether the avoidance of behavior that has potentially painful (physically or psychologically) consequences is facilitated by heightened emotional arousal.

Studies by Lykken (1957) and by Schachter and Latané (1964) demonstrated that psychopathic criminals, who are often described as without fear or guilt, failed to avoid errors punished with shock in a lever-maze learning situation. (At each "choice point" in the "maze" there was a correct response, an incorrect and shocked error, and several possible wrong options not resulting in shock.) The demonstration by Schachter and Latané that psychopaths would learn to avoid shocked errors when pre-aroused with an adrenalin injection (contrasted with a placebo injection) provided significant evidence for the conclusion that nonaroused psychopaths disregarded the shock because of a lack of normal emotional response to that punishment. Other work by Schachter and Ono (Schachter \& Latané, 1964) demonstrated that college students would cheat more under tranquilizer (chlorpromazine) conditions than under placebo conditions. Those findings gave considerable support to the traditional view that avoidance behavior (including the avoidance of behavior seen as immoral) is mediated, or at least facilitated, by emotional arousal. It is only a short conceptual step to the normally accepted idea that moral transgressions are resisted in part through the aid of conditioned fear, anxiety, shame, and guilt, an analysis akin to the two-factor avoidance theory advanced by Mowrer (1950). The twofactor avoidance theory states that avoidance is facilitated by conditioned emotional responses that increase as the individual approaches the forbidden behavior and decrease (providing reinforcement) as the individual avoids or retreats from that behavior. That theory provides our starting point.

\section{EMOTION ATTRIBUTION AND MORAL BEHAVIOR}

Schachter and Singer (1962) demonstrated that emotional arousal artificially induced by adrenalin injection could be experienced as different emotional states (anger or euphoria), depending on the different attributions made in different experimental contexts. The application of that idea to our avoidance formulation, as developed above, would lead to a theoretical elaboration. Identical levels of emotional arousal, resulting from a conditioned emotional response to (planned) transgression behavior, might lead to very different reactions depending upon the attributions made about the causes or meaning of that emotional response. Actually, this statement represents little more than the imposition of attribution-theory language on an idea occasionally articulated by socialization theorists. In the words of punishment researchers Walters and Parke (1967), it 
may be that "social conformity is not facilitated by arousal per se but only by emotional responses that are associated with, or are contingent on, certain kinds of cognitive structuring [p. 220]." The first study in the next series of research was an attempt to ascertain whether the attributions an individual made about emotional arousal naturally induced in a temptation situation could be manipulated to alter the frequency of tempted behavior substantially. Since other research had clearly demonstrated that the quantity of arousal was important in avoiding punished errors and temptation, this initial research posed the question of whether qualitative differences in emotional states under constant arousal conditions would yield similar results. This question, if answered affirmatively, would prove far from academic, for it could provide one of the keys to understanding how cognition plays a role in modulating the impact of emotional inhibition without immediately changing the quantity of emotional arousal. In nonmoral contexts, we are used to viewing such emotional-cognitive interactions. Even if we are slightly acrophobic, for example, we know that if we can retain our belief that a roller coaster ride is safe, and if the emotional arousal is not overwhelming, we may experience the arousal state as positive excitement rather than negative fear. In our attribution language system, we would say that the attribution of the cause of the emotional experience to the speed and fast stimulation changes rather than to danger allows the emotional arousal to be experienced as noninhibitory; we continue to seek out rather than to avoid the roller coaster.

In the first study of this series, done with the aid of Pamela Osborne Munter (Diestbier \& Munter, 1971), I attempted to study the impact of different emotion attributions on cheating. Recruited for a study on the impact of a vitamin supplement on vision, subjects ingested a placebo pill and participated in a vocabulary testing exercise like that described previously, while waiting for the pill (supposedly containing the vitamin supplement) to take effect. The vocabulary test was introduced as a delay task, but subjects were told that the board of psychologists would probably get in contact with them if they scored less than 20 . Subjects were then exposed to the autokinetic illusion to verify that the pill really did have psychoactive effects and were subsequently given an opportunity to cheat on their vocabulary test, although they were warned (as in all cheating research), "Do not change any answers." At the beginning of the study and immediately prior to the opportunity to cheat, half of the subjects were told to anticipate possible side effects of autonomic arousal (e.g., heart acceleration, face flushing, etc.), and half were told to expect benign side effects irrelevant to autonomic arousal.

In that study $49 \%$ of the 47 subjects who had anticipated arousal side effects cheated, compared to $27 \%$ of the 48 control (nonarousal) subjects $(p<.05$, by Fisher's exact text, one-tailed). But the entire effect was due to the male subjects. Follow-up research (Dienstbier, 1972) indicated that the effect held for women, too, provided that the threat for failure was made less intense; it was concluded that either the women experienced the threat of Study 1 as more 
attention-preoccupying than did the male subjects, so that they did not attend to the more subtle aspects of the study pertaining to the pill side effects, or that they were unable to attribute their higher emotional arousal to the pill. The hypothesis underlying those studies on cheating was confirmed, with those subjects who could attribute their emotional arousal to the placebo pill apparently experiencing their arousal differently, so that it did not play an inhibitory role as they considered cheating.

Of course there are alternative explanations of this type finding - explanations that do not assume that the vital process is the attribution of arousal to the pill. For example, there is a possibility that merely inducing the subject to attend to the arousal side effects might somehow cause the associated emotion to become reduced or dissociated from the temptation dilemma. In a second study discussed in the 1972 article, that question was experimentally addressed. In a four-condition study, half the subjects received no placebo but were told that they were in a "control" condition. It was explained to those "control" subjects that after the "real" subjects received the vitamin-related drug, we assess drug effects through a side effects checklist that those "real" subjects fill out. Therefore, it was explained, the possibility exists that suggestions induced by the questions on the checklist might result in the side effects being reported by the "real" subjects when they really are not experienced. To ascertain whether this checklist suggestion effect was real, "control" subjects were told that they would be run through exactly the same study as the "real" subjects, except that they would receive no pill. This is exactly what was done. Half of the "control" subjects were given drug information and a checklist concerning the arousal side effects, while the second half received the benign side effects description and checklist. "Control" subjects were asked to "look into themselves conscientiously, just as 'real' subjects did," to assess whether they experienced the symptoms listed on their side effects lists. The other two conditions of the study received the "arousal" and "benign" placebo pills in conditions that essentially replicated the Dienstbier and Munter (1971) study. In the "control" conditions, merely attending to arousal side effects did not facilitate cheating, but the facilitory effect of the arousal placebo in the replication conditions was observed. The statistically significant interaction helped to establish that the hypothesized emotion-attribution process may be the best logical explanation for the increased cheating with the arousal placebo.

The success of the studies described above led to interest in working with the attributional processes that would be employed by children as they faced temptation. I speculated that those attribution processes would be shaped by the socialization practices of the parents, since different socialization techniques would provide different emotion-attribution information. For example, if physical punishment followed stealing, would the punishment itself become so salient and obvious a source of the child's emotional discomfort that the child would attribute emotional discomfort to the punishment rather than to the stealing? 
If so, in future temptation (to steal) situations, would the conditioned emotional response be attributed to the punishment rather than to the act of stealing? If, in the former case, the emotion was experienced as fear of punishment, would the emotion be as effective in preventing stealing than if equally intense emotions in anticipation of stealing were attributed to the act of theft itself? It was hypothesized that the externally attributed emotional discomfort (to the punishment rather than to the act) would be less effective in inhibiting transgression when the situation was perceived as detection-free. That formulation is untestable for ethical reasons; but the hypothesized ineffectiveness of external emotion attributions is testable if external attributions are induced through verbal rather than physical techniques.

\section{Studies of Self-Control with Children}

The research that was subsequently undertaken to explore those questions was therefore restricted by practical and ethical considerations to testing whether children would react differently in a detection-free situation after they had been given the attributions that previous emotional discomfort (from a failure in a similar situation) was due to being "found out for doing the wrong thing" (external) as compared to attributing their emotional arousal simply to "having done the wrong thing" (internal). If merely giving different verbal attribution information in an experimental context substantially altered subsequent behavior in a "detection-free" situation, evidence would be provided to support the conclusion that like the college freshmen in the cheating studies, the emotional attributions children make are relevant to moral behavior and extremely susceptible to influence; hence such processes could be an important key to understanding socialization differences.

In the placebo research with adults, emotion attributions were manipualted in a manner quite dissimilar from real-life experiences. This use of techniques not encountered outside of the laboratory was undertaken in order to establish that attribution manipulations could induce differential cheating. The shift to research with children, however, represented an examination of emotion-attribution at quite a different level from that in the placebo-cheating research with adults, for the emotion attributions that were induced with children are closer to potential real-life manipulations.

In the first two studies (Dienstbier, Hillman, Lehnhoff, Hillman, \& Valkenaar, 1975) of the series with second-grade children, a three-part procedure was developed in which different children were first asked to watch a slot car that supposedly had a problem. After their failure at that watching task was dicovered by the experimenter, their emotional responses were attributed to being found out (external) or to having done the wrong thing (internal). The children were subsequently left alone, watching the car for a period of 12 minutes with their attention to the task timed after the situation was changed so that they believed that they could not again be detected for not watching the slot car. Since this 
procedure is presented in detail elsewhere (Dienstbier et al., 1975), it will be presented here but briefly and only the results from the second of the first two studies will be considered.

In Study 2 of the research with children, second-grade identical and same-sex fraternal twins were used as subjects, with one of each twin pair in each of the two experimental conditions; Steve Slane and Gail Zimmerman worked diligently with me in Study 2. The subject population was chosen since environmental and genetic differences (and hence error variance) are nearly equated between conditions, permitting a sensitive matched-pairs analysis of the results; differences between the means of the two experimental conditions would not be altered by this choice of subjects, however.

In the first phase of Study 2, the randomly chosen participating twin was told that the slot car he was to watch was very old and that it might break if it fell off the track. It was explained to each twin that recent problems with the slot cars included the cars occasionally going too fast so that they jumped the track but that when that was about to happen a "trouble light" on the side of the "control" (observation) booth would go on. The child was then to push in the level indicated on the side of the booth to prevent the "accident." It was explained that the man who fixed the toys would soon be called by the experimenter but that he could not fix the slot car track unless it was well "warmed up." The child was then asked to help by watching the slot car run on the track during the experimenter's absence to "call the toy man"; the experimenter then left the room. Immediately following the child's transgression to the set criterion (not watching for 6 continuous seconds), the slot car was made to jump the track and the "trouble light" was turned on; the slot cars were controlled by an observer hidden in a one-way observation booth in the toy room. The experimenter, having been signaled by the observer, returned immediately after the slot car accident and accompanied the child to another room (allowing the observer to remain blind). The experimenter then became aware of the first twin's condition and delivered the independent manipulation. Except for the attribution message itself, the language and emphasis of the two manipulation scripts was identical. The excerpt below is a brief portion of the external manipulation script with the italicized parts indicating the phrases added to modify the internal script to external:

"I bet you feel a little bad now that I found out the car fell off. I've seen other kids feel bad when someone found out they weren't able to do exactly what they were supposed to do. When the other kids who tried to watch the car couldn't, they felt bad when I found out too," etc.

At the end of the independent manipulation, delivered in a gentle and warm manner, the child and experimenter returned to the toy room. The child was told that since he/she knew how to start and control the new "unbreakable" slot car, that during the ensuing period with the experimenter locked out (and with no key), "even if it (the slot car) did fly off the track, I'd never find out, 
since you could put it back yourself and I can't come right in with the door locked." After establishing a "secret knock" so that the child would know when the experimenter had returned, the child was left "alone" in the locked (from the outside) room for 12 minutes of slot-car watching. At the end of the 12 minute period, all children were praised lavishly for their apparently excellent performance and exchanged with their opposite-condition co-twin.

The average time of transgression (not watching the slot car) was 322 seconds for the external-condition twins, compared to 177 seconds for the internal condition children $(t=8.0, p<.001)$. Aside from the mean superiority of the watching behavior of the internal twins, a remarkable data pattern emerged; for each of the six twin-pairs run, the external twin transgressed approximately twice as much as the internal twin, a finding not dependent upon which condition was run first.

An analysis of the procedure from the child's standpoint may be useful in putting the powerful data of Study 2 in perspective. First, when the first slot car jumped the track, followed almost immediately by the entrance of the experimenter, the suddenness of all that happened seemed to leave most children quite surprised; most subjects displayed emotional arousal as evidenced by agitation and attempts to remedy the situation and/or to provide excuses for the accident. Second, although the experimenter acted warmly and kindly toward the child, he was a male (hence less often encountered in this type of situation by secondgrade children), and he was a relative stranger (hence somewhat unpredictable and arousal provoking). In response to some combination of those factors and the experimenter's warm delivery of the independent manipulation, most children responded quite positively by apparently trying to pay attention. Finally, the task was a new one, with which the children had not had extensive previous experience, so that they were (presumably) somewhat more suggestible than if a more mundane task had been used. Since most factors, as described above, differ from typical socialization situations in the home or school, with the differences favoring more potential impact for our manipulation, it should not be expected that a similar level of single-trial success would be achieved with similar attribution manipulations in natural settings.

Although most early moral training is undertaken by socialization agents in circumstances of the child's heightened arousal following transgression (as in Study 2), I was curious if similar results could be achieved in an "innoculation" paradigm - a situation of reduced emotional arousal with emotion-attribution information given prior to any transgression or error. As the idea developed of exploring emotion-attribution procedures under conditions of reduced emotional arousal, the question of whether the arousal concept was necessary at all was confronted. An analogy to perceptual-motor functioning seems appropriate. In perceptual-motor tasks, when a skill such as driving a car is well learned, we take account of and respond to extremely small variations in directions, guiding the vehicle accordingly but usually without an awareness that is consciously articu- 
lated. It may be that we similarly learn to take account of even slight variations in autonomic arousal levels, responding and "correcting course" with (often) minimal or no articulated awareness. This belief in the influence of even slight arousal was clearly anticipated by William James (1890): "The changes are so indenfinitely numerous and subtle that the entire organism may be called a sounding-board which every change of consciousness, however slight, may make reverberate. . . Every one of the bodily changes, whatsoever it be, is felt acutely or obscurely, the moment it occurs [p. 450]." Although these observations do not conclusively establish the necessity of the arousal concept, they do encourage the continued use of the concept, especially in light of the earlier cited research. That is, it is apparent that most research subjects did not undergo strong arousal in the studies of Schachter and Ono (in Schachter \& Latané, 1964) and those previously cited cheating studies with adults by my associates and me; yet the subjects responded to a tranquilizer in Schachter's research and emotion-attribution information about the (placebo) pill in our research as if their emotional arousal were quite significant.

The third study in this series with children, undertaken with the aid of Gil Tunnell and Cynthia Gallentine, was conducted to ascertain whether the emotionattribution procedure would yield similar results under conditions of reduced emotional arousal and when given prior to any temptation or failure.

Data were gathered from 10 pairs of same-sex fraternal and identical twins, 2 pairs of which were in first grade, with the remaining 8 in second grade. As in Study 2, the randomly chosen participating twin was instructed in the necessity of running the slot car to warm it up and on the procedures for preventing a slot-car accident.

But we eliminated any personal failure experience and attempted to minimize the emotional arousal of our subjects by telling them about a child who helped the toy room experimenter "yesterday" who did not do a good job watching; the slot car therefore jumped the track. Together the experimenter and child discovered the slot car to be broken - a result that supposedly could only happen to such a "very old" slot car.

The experimenter and the child then left the toy room (to aid in keeping the observer blind) to find a "new" slot car that the child would watch. During that absence the experimenter became aware of the (first) twin's condition and administered the independent manipulation, which was similar to that used in Study 2. The external passage below, representing the first two sentences of the independent manipulation, has the phrases italicized that represent those added to change the internal script to the external version:

"When the car fell off before, yesterday, when that other kid was supposed to be watching it, he felt very bad when I found out. I know he did, because he told me how bad he felt that I found out the car fell off."

Upon returning to the toy room, the child was told that although this new slot car could not break if it flew off the track, it would be bad for it to jump 
the track many times; constant attention to the car and trouble light would therefore be required to prevent accidents. The locked toy room door and secret knock portions were similar to Study 2. To make sure that subjects understood that their conduct was free from detection, they were told: "Remember, this is a new car and so it won't break even if it does fly off, and you know how to put it on and how to start it up. And the door will be locked so I can't come right in. So even if it did fly off the track, I'd never know." The experimenter then left the room, remaining out for 12 minutes, during which the child's attention to the constantly running slot car was monitored by the hidden observer.

Mean seconds transgressing (not watching) for the internal-condition twins were 188, compared with 346 seconds for the external-condition co-twins $(t=2.54$, sig $<.02$, one-tailed $)$.

Although Study 3 demonstrated that an inoculation procedure under apparently lower arousal levels could be similar in power to the Study 2, procedure utilizing prior failure, an even more convincing demonstration would be effected if children could be induced to make internal (vs. external) attributions through the use of materials not directly relevant to the dependent measure task. That is, one problem for the unambiguous interpretation of these studies with children is that it is possible that the internal manipulations drew more attention to the dependent measure task, or somehow made that task seem more important, etc.

Subsequent research with children was designed to answer the question of whether stories with internal or external emotion-attribution themes would differentially effect behavior in a difficult ("detection-free") watching task that would be presented to the children as unrelated other research. Although the initial research, conducted with the aid of Arleen Lewis, Charles Kaplan, Max Lewis, and Keith Willis, was successful in demonstrating superior watching performance from second-grade children after listening to internally oriented stories (heroes feeling good or bad due to their own performance, contrasted to external stories with feelings dependent upon others knowing), subsequent studies in our lab failed to replicate that effect; and I feel no confidence in our initial positive findings.

The positive outcome of such studies would have relevance beyond that of allowing greater certainty in the interpretation of the research with children. If it could be demonstrated that general internal emotion-attribution information given in a nonarousing context can be applied by individuals in specific moral situations, then the potential for developing moral training curriculae based upon this potentially powerful technique would be established.

Fortunately, research with college-age adult subjects has been successful in demonstrating this effect. The first series of research reported in this chapter (Dienstbier et al., 1977) utilized "reading comprehension test" materials to induce subjects to accept either internally or externally oriented emotionattribution beliefs about the functioning of conscience. But differences between those two manipulations were not found in the three studies reported; the only 
differences that consistently emerged were between the passages relating to morality (both internal and external) and the control condition material (dealing, in Studies 2 and 3, with memory). Fortunately for understanding the problems of Studies 2 and 3, a manipulation check question was included in the test questions; the question asked experimental condition subjects to indicate what the "final step" was in the development of morality. One of the two possible answers was externally oriented toward parental punishment, whereas the other was internally oriented toward one's own moral principles. The question was answered correctly by only $62 \%$ of the subjects in Study 3 . Since chance alone would yield a base rate of $50 \%$ correct, it was apparent that differences between the internal and external conditions were only weakly established, with approximately $24 \%$ of the subjects knowing the right answer (and half of the remaining $76 \%$ of the subjects guessing the correct option, yielding the $62 \%$ correct figure).

To strengthen the internal vs. external manipualtion in Study 5 , those passages were completely rewritten. In all other critical ways, Study 5 was identical to Study 3, being supposedly the thesis research of the graduate student assistant; this study was conducted with the able assistance of Lynn Kahle. It was predicted that with the distinction between the internal and external emotion-attribution passages much better defined, the external condition and control condition cheating rates would be closer, with the internal condition cheating rate being significantly less than the other two.

Freshmen women subjects were recruited exactly as in Studies 2 and 3 to participate in a study "involving verbal testing." Those subjects who read the one-page, internally oriented passage on "The Development of Moral SelfControl" read that

Even if the child has never been scolded or punished by parents, the child may begin to experience emotional tension when considering the violation of moral rules about things such as lying, cheating, or stealing ... the individual will resist temptation to avoid the emotional tension even though no one else may ever know of the transgression ... as we mature, the pleasure which we anticipate from knowing that we have acted morally correct remains a strong motivating force in helping us to be strong in the face of temptation. ... Research has demonstrated that often very strong feelings of emotional tension result from individuals violating their own moral values, even though other people important to them do not know of those violations.

Comparable passages from the externally oriented passage were as follows:

After being scolded or punished a number of times by parents or others, the child begins to experience emotional tension when considering the possibility of being found violating the moral rules about things such as lying, cheating, or stealing ... the individual will resist temptation to avoid the emotional tension which is tied to the risk of being found out ... as we mature, the pleasure which we anticipate from others knowing that we 
have acted morally correct remains a strong motivating force in helping us to be strong in the face of temptation ... research has demonstrated that often very strong feelings of emotional tension result when other people who are important to us discover and confront us over violations of moral values.

In addition to the differences in the internally and externally oriented passages as sampled above, at the end of each of the passages a "study question" was added to further involve the subject in thinking about morality in the manner described in each passage. Subjects were told that if they thought carefully about the passage and the question it would help them in the later reading-comprehension questions. Internal condition subjects were asked, "Can you think of any time recently when you were confronted with a moral choice but resisted transgression and remained strong due to feelings of emotional tension associated with your knowledge that the transgression violated your own moral values?" External subjects read a similar question ending with "... due to feelings of emotional tension associated with you knowing that other people might find out that you had transgressed?"

As in the previous studies of this type, after answering the first set of readingcomprehension questions, the subjects were given the right answers to the vocabulary test during the "delay" period and an excuse to use their pencils. As in Study 3, they were told that in order to avoid having to work an extra semester on his doctoral dissertation research, the researcher needed accurate data, etc.

The manipulation check indicated that a much better distinction between the independent manipulation passages concerning morality was achieved, with $83 \%$ of the subjects choosing correctly the internally or externally oriented option to the manipulation check question following the delay period, indicating that $66 \%$ knew the correct answer. As always, suspicious subjects were eliminated via a detailed, funnel-type (Page, 1971), postexperimental questionnaire.

As predicted, whereas only $15 \%$ of the 66 internal-condition subjects cheated, $30 \%$ of the 66 external subjects and $31 \%$ of the 61 control-condition subjects cheated. By chi-square tests, the frequency of cheating in the internal condition is significantly different from that of the external condition (chi-square $=4.31$, $p<.05$ ) and significantly different from the control condition (chi-square $=4.60, p<.05) .^{1}$

\footnotetext{
${ }^{1}$ It is of some interest to note, because social psychology is currently involved in discussions of the impact of social psychological knowledge on social change, that the independent manipulation in this study consisted of passages discussing two psychological theories, each having some claim to validity. That is, the external passage was essentially a presentation of the two-factor theory of avoidance (avoiding temptation to avoid previously conditioned emotion responses), whereas the internal manipulation was essentially the theory of selfcontrol presented in this paper and previously by Dienstbier et al. (1975). Differential cheating rates were achieved, then, by reading two different current psychological theories.
} 


\section{RESEARCH SUMMARY AND GENERAL THEORETICAL ISSUES}

It is useful now to consider the implications of all the emotion-attribution research reviewed so far for the purposes of summary and in order to explore that research for general conclusions not obvious when viewed piecemeal. The initial research with college students was presented to establish the importance of emotionattributions in making moral decisions, using a placebo pill manipulation that had very little apparent mundane or real-world realism. On the other hand, the research with conceptually similar phenomena with children presented manipulations that had far more mundane realism, such that it would not be difficult to speculate productivity about direct applications of that research to real-life socialization problems. But in changing significantly both the age of subjects and the form of the manipulation between the initial adult and the subsequent child research, we had only the theoretical bridge of emotion-attribution theory to join those two quite different research series. The final study presented above, using the reading comprehension approach to independent variable manipulation, substantially reinforces that conceptual bridge, for the manipulation content (e.g., "the individual will resist temptation to avoid the emotional tension even though no one else may ever know of the transgression") was purposefully designed to resemble that of the research with children (e.g., "He told me he would have felt bad even if I didn't find out"). The major value of that study, however, is the finding that adults were able to apply that general emotionattribution information about morality to a specific cheating situation. Although that finding would be more useful if it could have been demonstrated with young children as well, it is likely that our failure to demonstrate such a generalto-specific transition with children was due to working with children who were too young (second grade).

Another theme emerges from the research program as a whole other than the apparent convergence of support for the emotion-attribution analysis. It does appear that children and young adults alike are remarkably susceptible to external influences in the attributions they make about the causes and meanings of their emotional arousal.

\section{How Attributional Processes Affect Behavior}

There are apparently three ways in which the attribution of emotion to an irrelevant source may affect the impact of that emotional arousal on subsequent behavior. Any or all of these effects may influence the role of emotional arousal in resistance to temptation.

The major emphasis derived largely from the research presented above has been that emotional arousal attributed to an irrelevant source simply becomes less effective in influencing behavior than if the source of the emotional arousal is experienced as relevant. For example, one may make attributions, which are essentially cognitive, that an emotional response is due to acrophobia on a high 
bridge or due to fear of detection in obviously safe situations. Although the quality of the emotional experience may change little or not at all under such circumstances, if the emotional arousal is of low or moderate intensity, it may be relatively easy and logically consistent to override the avoidance tendency motivated by the emotional state. This response somewhat resembles the classical psychoanalytic defense of "denial," but it should be increasingly more difficult to accomplish with increasing levels of negative emotion. The ineffectiveness of the arousal (placebo) pill manipulation with women in the initial emotionattribution study discussed previously was probably due in part to this phenomenon of increased difficulty in acting against the emotion when the emotion is intense. Similarly, Nisbett and Schachter (1966) found that under high-fear conditions, subjects would not attribute shock-induced arousal to a placebo pill with "arousal" properties, though such an effective attribution to the placebo (allowing more shock tolerance) under low-fear conditions did occur.

The second way in which the attribution of emotion to "irrelevant" sources may attenuate the impact of that emotion is through the quality of the emotion changing as a result of that reattribution. This result is probably more likely when a mixture of situational cues is present, some of which make positive and some negative emotions relevant. As suggested in the example used early in this chapter, the roller coaster may prove very exciting, even to the mildly acrophobic rider, if positive cues (other people laughing, the fast motion, etc.) are present and if the negative emotional state is perceived to be due to irrelevant sources (e.g., the rider perceives the danger as nonexistent, so the fear is due to personal and irrelevant deficiencies). Which of the cues are responded to will depend in part upon the chronic dispositions and needs of the individual. For example, the intense need for excitement believed to be common to the psychopath (Hare, 1970) may dispose such an individual to regard cues associated with negative emotional states (objective danger, etc.) as irrelevant (Yochelson \& Samenow, 1976). If negative cues are suddenly perceived as relevant, however, the positive emotional state may quickly revert to a negative experience. This re-experiencing of a different emotional state due to focusing upon selective cues has been termed "drive displacement" by Epstein (1967), who noted that novice skydivers often experience outbursts of anger prior to jumping, while steadfastly denying the experience of fear. Perhaps Frued observed these processes in developing the "reaction-formation" concept.

Finally, there is evidence that if the source of emotional arousal is seen as irrelevant, the emotional response will extinguish more quickly than if the emotion is seen as situationally appropriate. Loftis and Ross (1974) demonstrated that an emotional response would extinguish more quickly with continued presentation of the conditioned stimulus if subjects believed that the response was not due to the presented stimulus. This phenomenon is also quite likely to be observed mainly at low emotional arousal levels, for case histories are numberous of phobic individuals failing to experience extinction of their emotional reactions to stimuli that they knew (cognitively) to be "irrelevant." 


\section{SOCIALIZATION}

The various attributional messages that are potentially imparted by different socialization techniques can lead to different behavioral results following temptation through any or all of the three processes described above. Additionally, other variables are relevant in socialization, complicating prediction even further. Thus while each socialization technique may lead to different attributions about emotional arousal, each may be applied at varying levels of intensity, creating differing arousal levels. Additionally, each child has a different ability to generate and sustain emotional arousal, and children will certainly differ in their readiness and ability to make attributional inferences from the same situation. The characteristics of the socialization agent, the background variables of immediate environment (physical and social), and the relationships that exist between the socialization agents and child will also influence both the level of emotional arousal generated by any socialization interaction and the child's attributions about the cause and meaning of that emotional response. All these variables could interact in determining the effectiveness of any approach to the socialization of moral self-control for each individual. Such complexity must lead to extreme caution in assuming the validity of statements about the overall superiority of specific socialization techniques; it is not surprising that research on the success of most techniques has been quite inconsistent (Hoffman, 1970). Although the potential interactions of relationship, individual differences, and socialization techniques are far too numerous and complex for a comprehensive analysis in this chapter, I will discuss some of the more significant factors and relationships. Many of these analyses are admittedly highly speculative, and it will be obvious that much research remains to be done before even moderate certainty is likely.

The ability to generate and sustain emotional arousal may be one of the most important individual difference variables relating to socialization success. Such differences, often labeled "temperment," have been identified by many researchers (e.g., Cattell, 1965; Buss, 1975; Martin, 1971) as due more to heredity than to environmental variations (within American society). Most of the literature on socialization relates to that majority of children who come from the broad middle of the continuum of ability to generate and sustain emotional arousal and to those children who come from the high end, appearing anxious and overstimulated. This is simply because for such children, normal socialization works; whereas with psychopathic children - who evidence a lack of inhibiting emotional reactions - little socialization or therapeutic success is generally reported. Even within this normal group, the ability to generate and sustain arousal related directly to the level of socialization, as indicated by the recent work of Waid (1976). That work demonstrated that for a subject population recruited through the Rutgers newspaper, greater skin conductance in response to a loud tone corresponded to higher levels of socialization as indicated on the CPI Socialization Scale. This phenomenon has been previously noted between normal and psychopathic populations, with less skin conductance by the psycho- 
pathic group in response to noxious stimulation (Hare, 1970). There are two reasons for this more effective socialization of emotionally reactive children; obviously, such children would experience more inhibiting arousal when facing temptation, but it is also likely that less severe parental responses were needed (and therefore utilized) in socialization, with the result that the child would be more likely to attribute emotional arousal to the act of transgression, rather than to the parental confrontation.

Induction. As defined by Hoffman (1970), induction involves the explanation to the child of why certain behaviors are right or wrong; it is, according to Hoffman's review of socialization, a most effective technique for inducing moral self-control. An emotion-attribution analysis would support and explain that conclusion as follows: Following transgression and confrontation, even when interaction between parent and child will proceed on a verbal level, some arousal is quite likely, especially for the child who is higher in emotional reactivity. This arousal will be due to the child's recognition that the parent (or other socialization agent) is unhappy with the child, that the child has transgressed against a standard that may already be partially socialized (perhaps merely at the cognitive level), and that some inconvenience or pain to the child may be forthcoming. But by asking the child to focus upon the harm done by the act of transgression, the child is induced to attribute that emotional discomfort - whatever the real cause - to the transgression. When confronting later temptation, the emotional discomfort resulting from the contemplation of transgression should be experienced as relevant and should play a role in aiding the resistance to that temptation. Hoffman has convincingly presented the case that induction is the most effective technique for the development of self-control; I would suggest that this would be true for children in the middle to upper range of emotional responsiveness; the likely ineffectiveness of induction for emotionally unresponsive children will be elaborated below.

Punishment. The literature on morality and socialization indicates that when moral self-control is defined similarly to the manner used previously in this paper (resistance to temptation under circumstances of perceiving that detection for transgression is impossible), that punishment is ineffective - appearing to be negatively related to morality (Maurer, 1974). On the other hand, some research has suggested that love withdrawal or "psychological" punishment is positively related to self-control (e.g., Sears, Maccoby, \& Levin, 1957).

Punishment is obviously quite effective as a behavior control technique, either when punishing agents will normally be present during temptation periods (e.g., controlling social problems such as hitting adults) or if the organism is not sufficiently developed cognitively to be able to know that there are detection-free contexts or to recognize them with confidence when they occur. However, its major limitation in inducing moral self-control, as defined above, 
is that more than any other technique the act of punishment draws to itself the attribution of negative emotional arousal. The child with the stinging hand may find it almost impossible to attribute the resultant emotional state to the act of transgression rather than to the punishment. Yet, it is possible that judicious use of punishment could be useful in eliciting emotional arousal that might (in later similar transgression circumstances) be attributed to the transgression itself rather than to the early (in socialization) punishment, especially in less emotionally reactive children. However, remembering the relationship of misattribution and emotional arousal level, positive results with punishment should hold most for mild punishment of young children when it is delivered in conjunction with internal emotion attributions (e.g., "you feel bad because you transgressed," etc.). With older children who are normal in emotional reactivity, a paradoxical effect is predicted, with the more severely punished child manifesting less resistance to temptation, since such a child could make accurate emotion attributions about the external cause of the emotional arousal. There is some evidence of exactly that effect. In their chapter on the influence of punishment, Walters and Parke (1967) reference their own research in which the impact of punishment intensity and timing interacted for 6- to 8-year-old boys. High-intensity punishment was more effective in eliminating or delaying reaching for a "forbidden toy" in a 15-minute "alone" condition if administered early in the reaching sequence; however, it was the low-intensity punishment that was most effective if punishment was delivered late in the sequence (where it occurs in most natural socialization). They suggested that the late, mild punishment might have served as a more effective cue, allowing the association of the disapproved activity with disapproval more than would be the case for the high-intensity punishment. My interpretation would suggest that when elicited early in a behavioral sequence, the emotional arousal resulting from punishment may be mistakenly attributed to the act of transgression, since this attribution is facilitated by the temporal contiguity (but even this effect should hold only for relatively young children). On the other hand, once a transgression has been completed, if negative emotional arousal is then induced by a very salient (severe) external cause, the child should be able to clearly differentiate the punishment-induced emotional state from the previous state associated with the transgression itself, facilitating the attribution of the negative emotional state to the punishment. Thus a late, severe punishment should be particularly ineffective for normal children. Emotionattribution theory can therefore provide an articulate framework for explaining why punishment is negatively associated with the development of self-control when used in the home and classroom.

When punishment is inconsistent, it should be even less effective, since the child will be more able to correctly perceive the external cause of the negative emotional state if it does not always follow identical transgressions. Similarly, if an individual is punished very frequently, perhaps due to low emotional reactivity (hence slow avoidance learning), strict parents, or due to living in 
a particularly tempting environment, that individual too should learn more accurately the real causes of emotional arousal and hence should be less likely to attribute negative emotional arousal to the act of transgression. One can foresee the possibility of a vicious circle, with the lower emotional reactivity leading to less emotional conditioning, resulting in more punishment, which would in turn lead to more accurate attributions about the source of emotional arousal following transgression; the ultimate result would be that moral development would be substantially inhibited.

When punishment is "psychological" or love-oriented, on the other hand, some authors have suggested that it is effective in the hands of warm parents (i.e., Sears et al., 1957). If there is no specific salient and identifiable parental act of punishment in such cases, it may be easier for the child to misattribute emotional arousal to the act of transgression rather than to the punishment itself. In short, if both physical and "psychological" punishment induce similar arousal levels, the more tangible physical punishment should prove less effective for the development of self-control. When the child perceives the parents to be warm, it would be more difficult to attribute to them and to their act of punishment the negative emotional response from the punishment, making attribution to the transgression itself easier. We might also surmise that warm parents probably tend to use milder punishments and more explanations, facilitating internal attributions.

\section{Psychopathy and Emotional Arousal}

In his review of the psychological literature relating to psychopathy, Hare (1970) indicated the Group for the Advancement of Psychiatry has proposed that the term "tension-discharge disorder, impulse-ridden personality" be used in place of the term "psychopath" when applied to children. Hare (1970) described such an individual as one with "little anxiety, internalized conflict, or guilt ... with failure to develop the capacity for tension storage and for the postponement of gratifications [p. 5]." (For this chapter I continue to use the term psychopath for young and old.) Not only are psychopaths typically regarded as being "guiltless" and low in capacity for fear and/or anxiety, but as high in their need for stimulation and thrill seeking. We focus first on the implications of the psychopath being unable to develop or sustain emotional arousal from those socialization experiences that would cause negative emotional states in more normal children.

It should be expected, if a lack of powerful and sustained emotional arousal is the root problem of psychopathy and some habitual criminality, that the primary focus of socialization and correctional techniques for such individuals might be through procedures that reliably elicit high levels of emotional arousal (in normal children), provided that those techniques are consistently applied and contingent upon negative behavior. Hare (1970) has suggested that psychopathy "may very 
well represent the outcome of interactions between the characteristics (possibly congenital) of the child and the socialization techniques employed [p. 101]." He noted that cold, unaffectionate fathers who tend to be strict disciplinarians have fewer psychopathic children and that strict discipline tends also to decrease the incidence of adult psychopathy. But Hare's analysis should hold only if the strict discipline is consistently applied, for the reasons detailed above. Inconsistent, harsh discipline occasionally (noncontingently) applied should lead to opposite results, since accurate (external) attributions become quite likely under such a regime. We would therefore expect that even with strict and consistent discipline that real self-control, as defined herein, would be achieved only slightly by children who are chronically unresponsive emotionally, but that in detection-possible situations such procedures would result in socially acceptable behaviors.

The picture that emerges is of an emotionally unresponsive individual who is likely to become the target of increasingly harsh socialization as parents and others become desperate to achieve positive change. But while that punishment should lead to some conditioned emotional arousal when the psychopath faces temptation, it should be quickly discounted in detection-free situations by the psychopath as irrelevant, since correctly attributed to punishment. This would be particularly true if the harsh discipline administered were inconsistent. There is some evidence that a noncontingent, harsh environment is related to the development of psychopathic behavior (e.g., Hare, 1970; Mandler, 1964; Kohlberg, 1958) and that even though psychopaths do evidence normal levels of autonomic arousal under threatening conditions, they do not experience arousal as inhibiting emotion (Schachter \& Latané, 1964).

Let us return to the issue of the understimulated and stimulation-seeking side of psychopathy. Hare has reported that even in controlled laboratory situations, the psychopathic delinquent indicates a greater preference for levels of complexity and novelty (associated with seeking higher arousal levels) than normal controls. In their study of The Criminal Personality, Yochelson and Samenow (1976), though reluctant to use the term psychopath, described the habitual criminal as almost constantly seeking emotional stimulation, partly through turning to criminal activity; thus crime is not just the logical result of the lack of inhibitory control. Criminal activity may be experienced by the psychopath as a positive emotional stimulant.

Indeed the psychopath's apparent need for criminal activity for its own sake (rather than to remedy conditions of material deprivation, if we accept the thesis of Youchelson and Samenow) provides some support for the idea that the criminal experiences the emotional arousal associated with the risks of crime as a positive emotional experience. That enjoyment of risk is apparently attained through the elimination of the belief that capture is possible, rendering punishment-induced emotional arousal irrelevant. Yochelson and Samenow discuss a process they label "cutoff" in which the chronic criminal convinces himself that all forms of danger are irrelevant to the ensuing crime. 
It was suggested above that the misattribution of the cause of (and hence the nature of) certain emotions is maximized under conditions of low or moderate emotional arousal; the process of re-experiencing the emotional state associated with danger should therefore be relatively easy for the psychopath.

This reinterpretation of emotional arousal originally stimulated by punishment and later elicited by the temptation situation does not mean that all emotional states might easily be derived from that initial fear-stimulated arousal. Discrete emotion theorists such as Izard $(1971,1972)$ and Plutchik (1962) have suggested that certain emotions are somewhat alike in underlying arousal. It should therefore be easier to reattribute or re-experience certain emotional states as certain specific others, since some arousal components may be common to a limited few similar states. (Certain arousal components may be common to all emotional states that have sympathetic nervous system involvement, as emphasized by Schachter and Singer [1962].) Specifically, for the present issue, Hebb (1946) has noted that the arousal common to both fear and excitement allows easy transition between those two emotional experiences.

\section{CONCLUSIONS}

Often the imposition of a new theoretical system to a substantive area of venerable interest results in new insights into those traditional issues and problems. Frequently, however, as new systems are embraced by theorists, momentum carries the theory into areas well beyond its range of convenience, as evidenced by claims of insight qualitatively superior to that provided by other theoretical systems. In this chapter I have attempted to avoid both the image and the fact of exaggerated claims; in fact, the major insight developed in this chapter could be that the emotion-attribution approach leads to recognition that the issues of moral socialization are far more complex than traditional moral judgment or avoidance theories would suggest. In place of relatively simple universal insight into moral development and socialization, I offer a theoretical pool muddied by complexity. However, it is possible with continued research and development that emotion-attribution theory will provide a means for establishing some order, to the end that the most important elements of individual differences and of socialization practices may be identified. A more articulate understanding of the interactions of those elements may follow.

With several colleagues (Dienstbier et al., 1975) I have previously attempted to use emotion-attribution concepts to understand the interrelationship of moral judgment, as understood by Kohlberg (1958), with moral behavior approaches as derived from learning theory. Without resurrecting that discussion, I shall elaborate briefly on the process of moral decision making, using emotionattribution concepts. It was argued, in the paper cited above, that in our society the number of behaviors that elicit moral dilemmas are few, involving (usually) pain inflicted upon others, honesty, and theft or destruction of property. As we 
mature, it is likely that different attributions about the specific temptation situations will emerge; that is, with social and cognitive development, different elements of an honesty situation may be important in defining the moral relevance of potential action. (The initial reading-comprehension research with college students reflects and illustrates this process.) But emotional responses may arise even in situations where initial attributional processes were not conducive to such response, for it is likely that the conditioned emotional response to such situations will be less differentiated than those attribution processes. (The research by Schachter and his colleagues with adrenalin and with the tranqualizer chlorpromazine reflects the importance of the level of emotional arousal.) It is suggested that one of the ways in which the individual decides which of several behavioral choices are appropriate is through an assessment of the emotional arousal that follows thinking about each behavioral option. As the individual contemplates the behavioral options available, attempting simultaneously to make judgments about how the relevant value should be hierarchically ordered, emotion-attribution processes become important. Although our experience with our subjects suggests that individuals are not aware of making such attributions at a verbally articulate level, the research with adult subjects using placebo pills with "arousal" side effects, the final reading comprehension study with adults, and the research with children all reflect this process.

At each of the levels of decision making described previously, the degree to which emotion is actually elicited, the attributions made, and the control those attributions have over the meaning of the emotional response will depend on the indivudal's capacity to develop and sustain arousal and the past socialization history of the individual as that history influences both the quantity and quality of emotional response developed in specific temptation situations.

\section{REFERENCES}

Buss, A. H. A temperament theory of personality development. New York: Wiley, 1975. Cattell, R. B. The scientific analysis of personality. Baltimore: Penguin, 1965.

Davies, E. This is the way Crete went. Psychology Today, 1969, 3, 42-47.

Dienstbier, R. A. The role of anxiety and arousal attribution in cheating. Journal of Experimental Social Psychology, 1972,8, 168-179.

Dienstbier, R. A., Hillman, D., Lehnhoff, J., Hillman, J., \& Valkenaar, M. C. An emotionattribution approach to moral behavior: Interfacing cognitive and avoidance theories of moral development. Psychological Review, 1975, 82, 299-315.

Dienstbier, R. A., Kahle, L. R., Willis, K. A., \& Tunnell, G. Cheating as a function of emotion-attribution and moral value activation: Reactance vs. conformance. Unpublished paper, 1977.

Dienstbier, R. A., \& Munter, P. O. Cheating as a function of the labeling of natural arousal. Joumal of Personality and Social Psychology, 1971, 17, 208-213.

Epstein, S. M. Toward a unified theory of anxiety. In B. A. Maher (Ed.), Progress in experimental personality research (Vol. 4). New York: Academic Press, 1967.

Fortenbaugh, W. W. Aristotle on emotion. New York: Barnes \& Noble, 1975. 
Hare, R. D: Psychopathy: Theory and research. New York: Wiley, 1970.

$\mathrm{Hebb}, \mathrm{D} . \mathrm{O}$. On the nature of fear. Psychological Review, 1946, 53, 259-276.

Hoffman, M. L. Moral development. In P. H. Mussen (Ed.), Carmichael's manual of child development (Vol. 2, 3rd ed.). New York: Wiley, 1970.

Izard, C. E. The face of emotion. New York: Appleton-Century-Crofts, 1971.

Izard, C. E. Patterns of emotions. New York: Academic Press, 1972.

James, W. The principles of psychology (Vol II). New York: Henry Holt \& Company, 1890.

Kohlberg, L. The development of modes of moral thinking and choice in the years ten to sixteen. Unpublished doctoral dissertation, University of Chicago, 1958.

Langer, E. J., \& Abelson, R. P. The semantics of asking a favor: How to succeed in getting help without really dying. Journal of Personality and Social Psychology, 1972, 24, 2632.

Loftis, J., \& Ross, L. Retrospective misattribution of a conditioned emotional response. Journal of Personality and Social Psychology, 1974, 30, 683-687.

Lykken, D. T. A study of anxiety in the sociopathic personality. Journal of Abnormal and Social Psychology, 1957, 55, 6-10.

Mandler, G. Comments on Dr. Schachter's and Dr. Latanés paper. In D. Levine (Ed.), Nebraska Symposium on Motivation (Vol. 12), Lincoln, Neb.: University of Nebraska Press, 1964.

Martin, B. Anxiety and neurotic disorders. New York: Wiley, 1971.

Maurer, A. Corporal punishment. American Psychologist, 1974, 29, 614-626.

Mowrer, O. H. Learning theory and personality dynamics. New York: Ronald Press, 1950.

Nisbett, R. E., \& Schachter, S. Cognitive manipulation of pain. Journal of Experimental Social Psychology, 1966, 2, 227-236.

Page, M. M. Postexperimental assessment of awareness in attitude conditioning. Educational and Psychological Measurement, 1971, 31, 891-906.

Plutchik, R. The emotions: Facts, theories, and a new model. New York: Random House, 1962.

Schachter, S., \& Latané, B. Crime, cognition, and the autonomic nervous system. In, D. Levine (Ed.), Nebraska Symposium on Motivation. Lincoln, Neb.: University of Nebraska Press, 1964, 12, 221-273.

Schachter, S., \& Singer, J. E. Cognitive, social, and physiological determinants of emotional state. Psychological Review, 1962, 69, 379-399.

Schwartz, S. Normative influences on altruism. In Leonard Berkowitz (Ed.), Advances in experimental social psychology (Vol. 10). New York: Academic Press, 1976.

Sears, R. R., Maccoby, E. E., \& Levin, H. Patterns of child rearing. Evanston, Ill.: Row, Peterson, 1957.

Turiel, E. Social convention and morality: Two distinct conceptual systems. In Herbert E. Howe, Jr. \& C. Blake Keasey (Eds.), Nebraska Symposium on Motivation (Vol. 25). Lincoln, Neb.: Unibersity of Nebraska Press, 1977, in press.

Waid, W. M. Skin conductance response to both signaled and unsignaled noxious stimulation predicts level of socialization. Journal of Personality and Social Psychology, 1976, $34,923-929$.

Walters, R. H., \& Parke, R. D. The influence of punishment and related disciplinary techniques on the social behavior of children: Theory and empirical findings. In Brendan A. Maher (Ed.), Progress in experimental personality research (Vol. 4). New York: Academic Press, 1967.

Yochelson, S., \& Samenow, S. E. The criminal personality, Vol. I: A profile for change. New York: Jason Aronson, 1976. 